\title{
The impact of home parenteral nutrition on the burden of disease including morbidity, mortality and rate of hospitalisations
}

DOI:

10.1016/j.clnesp.2018.07.006

\section{Document Version}

Accepted author manuscript

Link to publication record in Manchester Research Explorer

Citation for published version (APA):

Burden, S., Hemstock, M., Taylor, M., Teubner, A., Roskell, N., Macculloch, A., Abraham, A., \& Lal, S. (2018). The impact of home parenteral nutrition on the burden of disease including morbidity, mortality and rate of hospitalisations. Clinical Nutrition ESPEN. https://doi.org/10.1016/j.clnesp.2018.07.006

\section{Published in:}

Clinical Nutrition ESPEN

\section{Citing this paper}

Please note that where the full-text provided on Manchester Research Explorer is the Author Accepted Manuscript or Proof version this may differ from the final Published version. If citing, it is advised that you check and use the publisher's definitive version.

\section{General rights}

Copyright and moral rights for the publications made accessible in the Research Explorer are retained by the authors and/or other copyright owners and it is a condition of accessing publications that users recognise and abide by the legal requirements associated with these rights.

\section{Takedown policy}

If you believe that this document breaches copyright please refer to the University of Manchester's Takedown Procedures [http://man.ac.uk/04Y6Bo] or contact uml.scholarlycommunications@manchester.ac.uk providing relevant details, so we can investigate your claim.

\section{OPEN ACCESS}




\section{Abstract}

2 Introduction: Home parenteral nutrition (HPN) provides fluid and nutrition essential for the survival of

3 patients with type 3 intestinal failure (IF). However, it is associated with complications and re-

4 admissions to hospital. This study aims to investigate the effect of HPN burden on mortality, morbidity

5 and hospital re-admission rates in patients with IF.

6 Method: This is a retrospective cohort study. All patients newly dependent on HPN discharged over a

7 4-year period between 2011- 2015 were included. Patients' characteristics, nutritional status and

8 diagnosis were recorded, along with frequency and duration of HPN administration. Outcomes

9 collected included hospital re-admissions, morbidity, catheter related blood stream infections

10 (CRBSIs) and mortality. Regression analyses were performed to estimate the rate of different

11 outcomes adjusted for prognostic factors.

12 Results: There were 210 patients included in the analysis, 561 separate HPN prescriptions equating

13 to 110,537 catheter days. A total of 196 re-admissions to hospital were recorded for a total of 5594

14 days, $69(33 \%)$ of these re-admissions were unplanned (2484 days in hospital). Principle reasons for

15 unplanned re-admissions included: CRBSIs $(n=31,45 \%)$; other sepsis $(n=10,14.5 \%)$ and abdominal symptoms $(n=9,13 \%)$. CRBSIs were recorded in $22(10 \%)$ patients, equating to a rate of 0.199 per

171000 catheter days. Days per week on HPN increased the relative rate (RR) of time in hospital due to any reason or for unplanned re-admissions, RR 1.50 (95\% Cl: 1.26, 1,78 p<0.001) and RR 1.39 (95\% $\mathrm{Cl}: 1.10,1.75 \mathrm{p}=0.006)$ respectively. However, there was no association between days per week on HPN and CRBSI occurrence.

Conclusion: Unplanned re-admissions for patients with IF accounted for a third of all hospitalisations in those on HPN and the majority were due to CRBSI. The number of HPN dependent days per week was related to all-cause unplanned re-admissions, although not to CRBSI rate. 
Intestinal failure (IF) is defined as the reduction of gut function below the minimum necessary for the absorption of macronutrients, fluid or electrolyte that requires intravenous supplementation to maintain health. ${ }^{1}$ There are three types of IF: types 1 and 2 describe acute conditions, while type 3 IF is a chronic condition, occurring in metabolically stable patients, requiring intravenous supplementation or home parenteral nutrition (HPN) over months or years. ${ }^{2}$ It may be reversible or irreversible. ${ }^{1}$ Administration of HPN can be over one to seven days per week via a central venous catheter (CVC). Home parenteral nutrition is a life-sustaining treatment for patients with type 3 IF and survival for these patients is primarily determined by the patient's underlying condition. ${ }^{3,4}$ The principal underlying conditions leading to IF include Crohn's disease, mesenteric ischaemia, and surgical complications. ${ }^{5}$ In some instances, and where appropriate, patients with underlying cancer may require HPN in palliation. ${ }^{6}$

Delivery of HPN does not come without risk and these include catheter thrombosis, catheter related blood stream infections (CRBSIs), IF associated liver disease (IFALD) and metabolic bone disease. In adult patients with benign chronic IF, death has been attributed to IFALD in $4 \%, \mathrm{CRBSI}$ in $8 \%$ and catheter-related thrombosis in $2 \%{ }^{7}$ The complications associated with HPN can also lead to significant morbidity, including the need for recurrent hospital admission for associated therapy combined with long-term clinic attendance for monitoring purposes. ${ }^{8}$ The effect of HPN dependence on patients' lives is substantial and has generated an increasing interest in evaluating quality of life (QoL) in this patient group. ${ }^{9}$ Issues important to patients that impact on $\mathrm{QoL}$ include the restrictive nature of overnight HPN leading to limited mobility, fatigue, social isolation, sleep interference and psychological problems associated with the highly regulated lifestyle required for intravenous feeding. ${ }^{10,11}$ Furthermore, the majority of those on HPN rarely return to gainful or satisfying employment adding to the sense of social isolation and lack of purpose. ${ }^{12,13}$ Moreover, patients also 54 state that the fear associated with complications impacts negatively on their QoL. ${ }^{14}$ Notably, removing some restrictions on lifestyle through maximising parenteral nutrition free days has been highlighted 56 as a way of improving QoL in patients on HPN. ${ }^{15}$ 
The frequency of HPN needed per week has also been reported to impact on CRBSI rate in some

59 studies, ${ }^{16,17}$ but not all published series. ${ }^{18,19}$ However, there are limited data detailing the health care

60 utilisation, re-admission rates and reasons for re-admission in the HPN population, nor data on the impact of HPN burden (as reflected by the number of HPN-dependent days per week). The aim of this study was therefore to determine the impact of HPN burden on clinical outcomes including hospital readmission rates, HPN-related complications and mortality.

The study design was a retrospective cohort longitudinal investigation. Data on patients were prospectively recorded and summarised by the clinical team. All patients referred for HPN to a national U.K. IF Unit at Salford Royal Foundation Trust were included in the study. All patients were over 16 years old and discharged between 01 January 2011 and 31 March 2015; all had type 3 IF. Patient demographics, nutritional status, underlying disease, central venous catheter type and management were recorded from an electronic patient record system. Clinical outcomes recorded included: number of CRBSI; rate of hospital re-admissions (all-cause and unplanned); number of days re-admitted to hospital and mortality rates. Diagnosis of a CRBSI was based on quantitative and qualitative assessment of central and peripheral pour plates as previously described. ${ }^{20,21}$ The reason for admission was also documented. Data on HPN prescriptions included duration on each prescription, volume, energy content, and number of infusions per week.

\section{Statistical analysis}

Regression analysis was performed to evaluate the effect of clinical outcomes and differences in factors including the number of HPN infusions per week; full details on covariates are presented in Table 1. Analyses were performed using SAS (Version 9.4) using proc glimmix on the following outcomes: rate of CRBSI; odds of death; time in hospital (separate models performed for all and unplanned admissions) and rate of hospital re-admissions (separate models performed for all and unplanned re-admissions). 
Dichotomous outcomes (mortality) were analysed using logistic regression, whereas count data (rate of CRBSI and rate and duration of admissions) were analysed using negative binomial regression. To better estimate the uncertainty in the data, a negative binomial model was chosen over a Poisson regression model. A negative binomial model allows for over-dispersion in the data and avoids the assumption in a Poisson model that the mean and variance are equal. ${ }^{22}$ As the nature of the study was to generate hypotheses, hypothesis testing was not performed, and confidence intervals and pvalues should be treated as descriptive. The dataset captured each new prescription for a patient over the period of data collection for HPN. The record captured where a change in HPN was observed in any of: number of days HPN per week, type of HPN (customised admixture glucose alone, customised admixture lipids alone or fluid-electrolytes alone), volume or energy. An individual patient could therefore contribute multiple records to the analyses; to account for the within-patient correlation, a random effect was fitted to patient identification in the data set. As the duration of each record varied, an offset to capture the duration of each record was used.

\section{Ethics}

Ethical approval was gained for this study from an Ethics Committee (Ref No 2015/096GRU) and NHS Trust was obtained prior to starting the study in accordance with governance arrangements.

\section{Results}

\section{Patient Characteristics}

There were 211 patients newly referred to our service discharged on HPN in to the community identified for the inclusion in the study, however one patient's HPN records could not be recovered, therefore, 210 patients were included in the analyses. Patients' characteristics and underlying diagnoses are displayed in table 2.

\section{Clinical Outcomes}

112 Clinical events and frequency HPN per week are shown in table 3. During the study period, there 113 were a total of 44 deaths; 23 occurred in patients with a known malignancy (causal to the need for HPN) and 21 in patients with underlying benign disease (Table 4). 
There were 22 CRBSIs that occurred during the study period, equating to $0.199 \mathrm{CRBSI}$ episodes per

1161000 catheter days. A total of 5594 hospital days were recorded for re-admissions during the 4-year

117 study period. Unplanned hospital re-admissions accounted for 69 out of 196 (35.2\%) of re-

118 admissions, of which the majority 34 (49.3\%) were related to CVC complications (Table 5). There were 28 out of $69(40.6 \%)$ re-admissions that occurred due to underlying IF disease and 7 out of 69

$120(10.1 \%)$ of re-admissions occurred due to other causes un-related to IF. All data, including the reasons for unplanned re-admissions to hospital, are shown in Table .

122

\section{Associations with HPN days per week}

124 Full regression analyses results are presented in Table 6. An increase of one day HPN treatment per week was shown to increase the re-admission (all-cause) days in hospital $(R R=1.50, p<0.001)$. In addition, an increase in one day HPN treatment per week was also seen to significantly increase the unplanned time patients spent in hospital $(R R=1.39, p=0.006)$. CRBSI rate (or death) were not associated with HPN requirement per week.

\section{Discussion}

131 This study provides a unique contemporary narrative of the impact of HPN on individuals in a national referral centre. As alternative therapies such as intestinal transplantation, small bowel lengthening and growth factors evolve to reduce the burden of HPN, it is vital to understand the current clinical outcomes of patients with type 3 IF initiated and then remaining on HPN. There were a total of 196 readmissions to hospital over the 4-year data collection period and from these unplanned admissions accounted for $33 \%$ of all cause admissions and 2484 inpatient days. The most frequently occurring reason for unplanned re-admission was catheter related issues with the most frequent issue being CRBSI.

In agreement with the findings from the present study the most frequently reported HPN complication requiring hospitalisation was CRBSI in a large European cohort in the first year after discharge ${ }^{23}$.

141 Other reasons for readmission included underlying disease in $27 \%$ of days admitted to hospital, HPN complications in $48 \%$ and other medical reasons in $25 \% .{ }^{23}$ However when shorter periods of time are evaluated at 30-days post discharge re-admission rates showed that from 224 patients on HPN 
$14431.6 \%(n=71)$ had unplanned re-admissions within 30-days of hospital discharge and the majority of

Incidence of re-admissions has been reported as an outcome for evaluating interventions as it is considered a major component of service delivery for patients on HPN. In 93 patients discharged from hospital there were 103 reported re-admissions over a 15 month period and all due to CRBSI, other reasons for re-admissions were not reported here ${ }^{25}$ In the evaluation of intestinal transplants readmissions are considered in the HPN costs and were cited as $€ 13,276$ for treatment introduction, $€ 77,652$ for annual maintenance including all HPN products, nursing support, outpatient visits, home care, and hospital admission for the treatment of HPN-related complications ${ }^{26}$ these costs are based on pricing index for 2012 in the Netherlands. ${ }^{27}$ For seven days hospital admission for HPN related complications the cost attributed were $€ 4258$ using these guidelines. In healthcare systems internationally there is an obvious benefit regarding the utilisation of resources to minimise HPN related complications.

In addition to the economic impact of re-admissions to hospital, a contemporary report of the clinical burden of HPN is important for patients. Type $3 \mathrm{IF}$ has a considerable effect on patient's lives associated with repeated hospitalisation and complications from $\mathrm{HPN}^{28}$ It is established that it is not just the hospital re-admission that impacts adversely on patients' QoL, the actual fear of re-admission and complications can equally harm an individuals' QoL. ${ }^{14,15}$

The present study found a CRBSI rate of 0.199 episodes per 1000 catheter days in new patients placed on HPN. This is a very low CRBSI rate when compared to the published literature. While a systematic review detailed a varied CRBSI rate reported from different centres of between 0.38 and 4.58 episodes per 1000 catheter days, ${ }^{29}$ a more recent series from the USA. reported a CRBSI rate as high as 11.5 per 1000 catheter days. ${ }^{30}$ It is clear that the reported CRBSI rate will vary according to the method of CRBSI diagnosis; indeed, relying on a clinical diagnosis rather than the more objective use of paired quantitative and qualitative blood cultures, as recommended by European Guidelines, ${ }^{8}$ can lead to over-diagnosis and unnecessary therapies. ${ }^{31}$ 
The diagnosis of CRBSI reported in the present study was based on paired quantitative blood cultures

174 in all patients, as previously reported.$^{21}$ Moreover, the patient cohort studied and duration of follow-up

175 may influence the CRBSI rate reported; for example, we previously reported a CRBSI rate of 0.38 per

1761000 catheter days in a very large cohort of patients needing HPN at our centre; the latter study

177 included patients new to, and those already established on HPN, followed up for a longer time period

178 between 1993 and 2011. More recently, we reported a CRBSI rate of 0.31 per 1000 catheter days in all patients (new patients to our service initiated on HPN and those already on established on HPN) managed at our centre between 2012 and $2016 ;^{32}$ again, the latter rate is likely higher than that reported in this paper, since the present study only included patients new to HPN and not those already established on HPN. Indeed, the duration of previous HPN has been shown to be associated with an increased risk of one or more CRBSIs. ${ }^{21}$ Nonetheless, the low CRBSI rates recorded also underscore the importance of an experienced and multidisciplinary IF team in managing patients in hospital and in the community. ${ }^{5}$

We suggest that the low levels of CRBSI reported is low because of a robust approach to the HPN catheter care program involving meticulous training by nurses of patients and family members to administer the PN. If self-administration is not possible, then home care nurses administer the PN according to the same meticulous catheter care protocol. By focussing on key catheter care principles (e.g. including hand washing, preparation of the aseptic pack, exit site dressings etc.) these low CRBSI rates are achieved without the use of antimicrobial locks.

We aimed to determine any association between the burden of HPN, as reflected by the number of days per week of PN, and clinical outcomes. While some, ${ }^{16,17}$ but not all ${ }^{18,19}$ studies found an association between HPN days per week and CRBSI rate, the present study did not. More frequent handling of the CVC through the week may place patients at higher risk of contracting an infection; however, there are a number of other factors that influence CRBSI rate, including the presence of a stoma, opiate use, individual caring for the catheter ${ }^{21}$. It is possible that no association was found with HPN days per week in this study because of the very low overall CRBSI rate recorded, such that the regression analysis was underpowered and unable to detect statistically significant differences. A further limitation of the regression analyses is that a large proportion of patients received HPN seven days a week, therefore meaningful categorisation of values less than seven days was difficult. As a 
result, HPN days per week were analysed a continuous variable, which assumed that the difference in one day HPN per week would have the same effect for each additional day added. An additional limitation of this study is that the data were retrospective. A MDT collected the data prospectively in patients' records and the data were then transferred to a database. It is possible that data on the incidence of complications, hospital re-admissions and days in hospital were incomplete. The study demonstrated that the number of days of HPN was associated with an increased number of days patients spent re-admitted to hospital. The reason for this association is unclear, but may reflect those needing more days of HPN having more severe underlying disease, as recently found in a very large European multicentre study which demonstrated that fluid volume requirements were a key predictor of loss if intestinal function and disease severity. ${ }^{33}$

In conclusion, the present study provides a detailed and contemporary evaluation of the clinical burden of HPN. These data are vital for payers, providers and, most importantly, patients. The study reports a very low CRBSI rate in a large cohort of patients placed on HPN managed at a national UK centre. The data also report a relatively low overall re-admission rate for patients dependent on HPN, a clearly important factor for pressurised health care economies as the overall incidence of HPN seems to be on the incline, ${ }^{34,35}$ but also a key factor in reducing morbidity and enhancing patients' quality of life.

\section{Statement of Authorship}

SB AM and SL designed the study and wrote the protocol, MH and NR undertook analysis and provided all statistical support, MT undertook preparation of data base and AT SL and AA provide clinical expertise. SB, SL and $\mathrm{MH}$ wrote the manuscript. All authors have inputted into the final manuscript and approved the final version.

\section{Conflict of Interest Statement}

SB and SL received unrestricted grant from NPS Pharma Limited.

SB and SL received unrestricted grant from Shire Pharmaceuticals. 
this work for the statistical analyses.

\section{Funding sources}

This research was funded by a grant from NPS Pharma, which was acquired by Shire

Pharmaceuticals in February 2015. In addition, SB and SL have previously received funding from

Shire Pharmaceuticals for investigator-initiated research projects unconnected with the development and writing of this particular research.

\section{References}

1. Pironi L, Arends J, Baxter J, et al. ESPEN endorsed recommendations. Definition and classification of intestinal failure in adults. Clinical Nutrition. 2015;34(2):171-180.

2. Lal S, Teubner A, Shaffer JL. Review article: intestinal failure. Alimentary pharmacology \& therapeutics. 2006;24(1):19-31.

3. Dibb M, Soop M, Teubner A, et al. Survival and nutritional dependence on home parenteral nutrition: Three decades of experience from a single referral centre. Clinical Nutrition. 2016;36(2):570-576.

4. Bozzetti F, Arends J, Lundholm K, Micklewright A, Zurcher G, Muscaritoli M. ESPEN Guidelines on Parenteral Nutrition: Non-surgical oncology. Clinical Nutrition. 2009;28(4):445454.

5. Dibb M, Teubner A, Theis V, Shaffer J, Lal S. Review article: the management of long-term parenteral nutrition. Alimentary pharmacology \& therapeutics. 2013;37(6):587-603.

6. Arends $\mathrm{J}$, Baracos $\mathrm{V}$, Bertz $\mathrm{H}$, et al. ESPEN expert group recommendations for action against cancer-related malnutrition. Clinical Nutrition. 2017;36(5):1187-1196.

7. Pironi L, Goulet O, Buchman A, et al. Outcome on home parenteral nutrition for benign intestinal failure: A review of the literature and benchmarking with the European prospective survey of ESPEN. Clinical Nutrition. 2012;31(6):831-845.

8. Pironi L, Arends J, Bozzetti $F$, et al. ESPEN guidelines on chronic intestinal failure in adults. Clinical Nutrition. 2016;35(2):247-307.

9. Wilburn J, McKenna SP, Heaney A, et al. Development and validation of the Parenteral Nutrition Impact Questionnaire (PNIQ), a patient-centric outcome measure for Home Parenteral Nutrition. Clinical Nutrition. 2017;10.1016/j.clnu.2017.04.004.

10. Staun M, Pironi L, Bozzetti F, et al. ESPEN Guidelines on Parenteral Nutrition: Home Parenteral Nutrition (HPN) in adult patients. Clinical Nutrition.28(4):467-479.

11. Baxter JP, Fayers PM, McKinlay AW. A review of the quality of life of adult patients treated with long-term parenteral nutrition. Clinical Nutrition.25(4):543-553.

12. Carlson GL, Maguire G, Williams N, Bradley A, Shaffer JL, Irving MH. Quality of life on home parenteral nutrition: a single centre study of 37 patients. Clinical Nutrition 1995;14(4):219-228.

13. Neves C, Chapman A, Burden S, Lal S, MacCulloch A. Systematic Literature Review of Health-Related Quality of Life In Patients Receiving Parenteral Nutrition. Value in Health.18(7):A630. 
14. Winkler M. Quality of Life in Adult Home Parenteral Nutrition Patients. Journal of Parenteral and Enteral Nutrition. 2005;29(3):162-170.

15. Culkin A, Gabe SM, Madden AM. Improving clinical outcome in patients with intestinal failure using individualised nutritional advice. Journal of Human Nutrition and Dietetics. 2009;22(4):290-298.

16. Bozzetti $F$, Mariani $L$, Bertinet DB, et al. Central venous catheter complications in 447 patients on home parenteral nutrition: an analysis of over 100.000 catheter days. Clinical Nutrition. 2002;21(6):475-485.

17. Santarpia L, Buonomo A, Pagano MC, et al. Central venous catheter related bloodstream infections in adult patients on home parenteral nutrition: Prevalence, predictive factors, therapeutic outcome. Clinical Nutrition. 2016;35(6):1394-1398.

18. Reimund JM, Arondel Y, Finck G, Zimmermann F, Duclos B, Baumann R. Catheter-related infection in patients on home parenteral nutrition: results of a prospective survey. Clinical Nutrition. 2002;21(1):33-38.

19. Pironi L, Paganelli F, Labate AM, et al. Safety and efficacy of home parenteral nutrition for chronic intestinal failure: a 16-year experience at a single centre. Digestive and Liver Disease May 2003;35(5):314-324.

20. Pittiruti M, Hamilton H, Biffi R, MacFie J, Pertkiewicz M. ESPEN Guidelines on Parenteral Nutrition: central venous catheters (access, care, diagnosis and therapy of complications). Clinical nutrition (Edinburgh, Scotland). Aug 2009;28(4):365-377.

21. Dibb MJ, Abraham A, Chadwick PR, et al. Central Venous Catheter Salvage in Home Parenteral Nutrition Catheter-Related Bloodstream Infections. Journal of Parenteral and Enteral Nutrition. 2016;40(5):699-704.

22. Zeileis A., Kleiber C, Jackman S. Regression models for count data in R. Journal of statistical software. 2008;27(8):1-25.

23. Van Gossum A, Vahedi $\mathrm{K}$, Abdel M, et al. Clinical, social and rehabilitation status of long-term home parenteral nutrition patients: results of a European multicentre survey. Clinical Nutrition. 2001;20(3):205-210.

24. Vallabh H, Konrad D, DeChicco R, et al. Thirty-Day Readmission Rate Is High for Hospitalized Patients Discharged With Home Parenteral Nutrition or Intravenous Fluids. Journal of Parenteral and Enteral Nutrition. 2016:0148607116664785.

25. Corrigan ML, Pogatschnik C, Konrad D, Kirby DF. Hospital Readmissions for CatheterRelated Bloodstream Infection and Use of Ethanol Lock Therapy. Journal of Parenteral and Enteral Nutrition. 2012;37(1):81-84.

26. Roskott $\mathrm{AM}$, Groen $\mathrm{H}$, Rings $\mathrm{EH}$, et al. Cost-effectiveness of intestinal transplantation for adult patients with intestinal failure: a simulation study. Am J Clin Nutr. January 1, 2015 2015;101(1):79-86.

27. Oostenbrink J KM, Rutten F Manual for cost studies, methods and standard prices for economic evaluation in health care.Amstelveen (The Netherlands): . Dutch Health Care Council. 2004.

28. Waal GH-d, Naber T, Schoonhoven L, Persoon A, Sauerwein H, Achterberg Tv. Problems Experienced by Patients Receiving Parenteral Nutrition at Home: Results of an Open Interview Study. Journal of Parenteral and Enteral Nutrition. 2006;30(3):215-221.

29. Dreesen M, Foulon V, Spriet I, et al. Epidemiology of catheter-related infections in adult patients receiving home parenteral nutrition: A systematic review. Clinical Nutrition. 2013;32(1):16-26.

30. Arends $\mathrm{J}$, Baracos $\mathrm{V}$, Bertz $\mathrm{H}$, et al. ESPEN expert group recommendations for action against cancer-related malnutrition. Clinical Nutrition. 2017.

31. Tribler S, Brandt CF, Hvistendahl M, et al. Catheter-Related Bloodstream Infections in Adults Receiving Home Parenteral Nutrition. Journal of Parenteral and Enteral Nutrition.0(0):0148607116686290. 


\begin{tabular}{|c|c|}
\hline Covariate & Definition \\
\hline Days of HPN per week & $\begin{array}{l}\text { Included in models as a continuous variable (minimum } 2 \text {, } \\
\text { maximum 7) }\end{array}$ \\
\hline Gender & Categorical variable: male or female \\
\hline Diagnosis & Categorical variable: Crohn's, surgical complications or 'other' \\
\hline Total time on HPN (1000 days) & $\begin{array}{l}\text { Continuous variable, time on HPN was defined as the time since } \\
\text { a patient started HPN }\end{array}$ \\
\hline Age & Continuous variable, where age is age at time of HPN onset \\
\hline CVC care $^{a}$ & Categorical variable: Nursed care or other (self or family care) \\
\hline $\mathrm{BMI}^{\mathrm{a}}$ & $\begin{array}{l}\text { Continuous variable, median BMI observed within time period of } \\
\text { HPN record }\end{array}$ \\
\hline Previous CRBSI & Categorical variable: yes or no \\
\hline Patient & $\begin{array}{l}\text { Included in the models as a random effect to capture within } \\
\text { patient correlation for multiple HPN records per patient }\end{array}$ \\
\hline HPN record length & $\begin{array}{l}\text { Length of time on HPN for the given record. Included regression } \\
\text { models as an offset. }\end{array}$ \\
\hline
\end{tabular}


${ }^{a}$ Covariate only included in CRBSI regression model; ${ }^{b}$ Covariate only included in the 336 deaths regression model. 
Table 2: Patient baseline characteristics

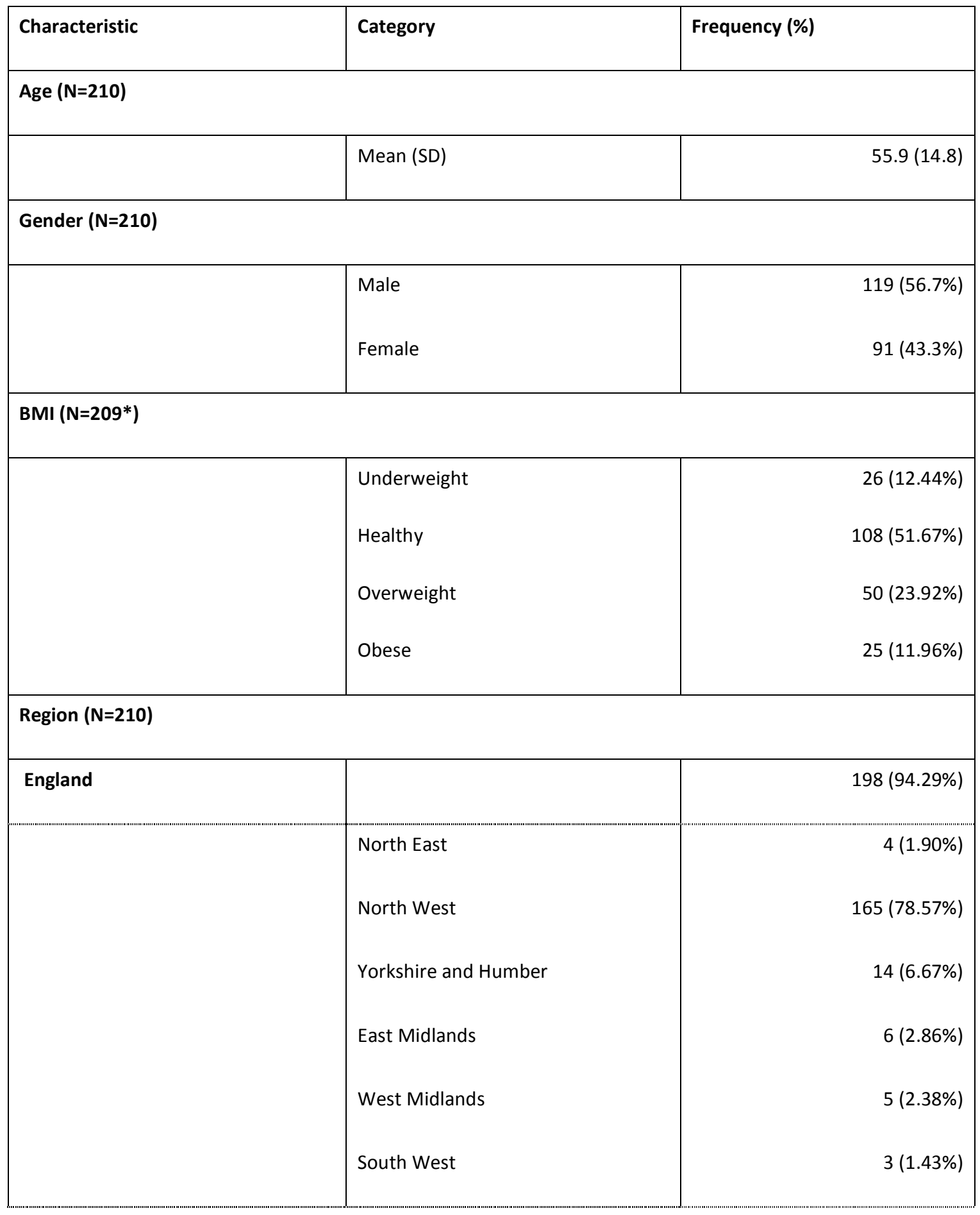




\begin{tabular}{|c|c|c|}
\hline Characteristic & Category & Frequency (\%) \\
\hline Wales & & $10(4.76 \%)$ \\
\hline Scotland & & $1(0.48 \%)$ \\
\hline Ireland & & $1(0.48 \%)$ \\
\hline \multirow[t]{2}{*}{ Offshore } & & $1(0.48 \%)$ \\
\hline & Isle of Man & $1(0.48 \%)$ \\
\hline \multicolumn{3}{|c|}{ Infusion care $(\mathrm{N}=\mathbf{2 1 0})$} \\
\hline & $\begin{array}{l}\text { Self } \\
\text { Family member } \\
\text { Nursed }\end{array}$ & $\begin{array}{r}80(38.10 \%) \\
10(4.76 \%) \\
120(57.14 \%)\end{array}$ \\
\hline \multicolumn{3}{|c|}{ IF diagnosis $(\mathrm{N}=210)$} \\
\hline & $\begin{array}{l}\text { Active malignancy } \\
\text { Crohn's disease } \\
\text { Motility disorders } \\
\text { Radiation enteritis } \\
\text { Scleroderma } \\
\text { Surgical complications } \\
\text { Vascular } \\
\text { Other }\end{array}$ & $\begin{array}{r}20(9.52 \%) \\
36(17.14 \%) \\
20(9.52 \%) \\
5(2.38 \%) \\
2(0.95 \%) \\
89(42.38 \%) \\
27(12.86 \%) \\
11(5.24 \%)\end{array}$ \\
\hline
\end{tabular}

Key: BMI, body mass index; IF, intestinal failure; $N$, number of patients

Notes: *patient 192 has no record of BMI 
Table 3: Rate of clinical events by home parenteral nutrition administered per week expressed as per 1000 catheter days

\begin{tabular}{|c|c|c|c|c|c|c|c|c|c|}
\hline $\begin{array}{c}\text { Days } \\
\text { per } \\
\text { week }\end{array}$ & no & $\begin{array}{l}\text { HPN } \\
\text { records }\end{array}$ & $\begin{array}{l}\text { Time } \\
\text { days }\end{array}$ & $\begin{array}{l}\text { Days in } \\
\text { hospital }\end{array}$ & $\begin{array}{l}\text { Admissions } \\
\text { all cause }\end{array}$ & $\begin{array}{c}\text { Unplanned } \\
\text { days in } \\
\text { hospital }\end{array}$ & $\begin{array}{l}\text { Unplanned } \\
\text { admission } \\
\text { all-cause }\end{array}$ & CRBSI & Deaths \\
\hline 2 & 11 & 11 & 2754 & $\begin{array}{c}18 \\
(6.536)\end{array}$ & $\begin{array}{c}5 \\
(1.816)\end{array}$ & $\begin{array}{c}18 \\
(6.536)\end{array}$ & $\begin{array}{c}1 \\
(0.363)\end{array}$ & $\begin{array}{c}1 \\
(0.363)\end{array}$ & $\begin{array}{c}0 \\
(0.000)\end{array}$ \\
\hline 3 & 27 & 34 & 8532 & $\begin{array}{c}67 \\
(7.853)\end{array}$ & $\begin{array}{c}11 \\
(1.289)\end{array}$ & $\begin{array}{c}26 \\
(3.047)\end{array}$ & $\begin{array}{c}2 \\
(0.234)\end{array}$ & $\begin{array}{c}1 \\
(0.117)\end{array}$ & $\begin{array}{c}2 \\
(0.234)\end{array}$ \\
\hline 3.5 & 3 & 3 & 85 & $0(0.000)$ & $\begin{array}{c}0 \\
(0.000)\end{array}$ & $\begin{array}{c}0 \\
(0.000)\end{array}$ & $\begin{array}{c}0 \\
(0.000)\end{array}$ & $\begin{array}{c}0 \\
(0.000)\end{array}$ & $\begin{array}{c}1 \\
(11.765)\end{array}$ \\
\hline 4 & 39 & 65 & $\begin{array}{c}1193 \\
3\end{array}$ & $\begin{array}{c}249 \\
(20.867)\end{array}$ & $\begin{array}{c}14 \\
(1.173)\end{array}$ & $\begin{array}{c}180 \\
(15.084)\end{array}$ & $\begin{array}{c}7 \\
(0.587)\end{array}$ & $\begin{array}{c}2 \\
(0.168)\end{array}$ & $\begin{array}{c}4 \\
(0.335)\end{array}$ \\
\hline 5 & 49 & 75 & $\begin{array}{c}1403 \\
9\end{array}$ & $\begin{array}{c}584 \\
(41.598)\end{array}$ & $\begin{array}{c}20 \\
(1.425)\end{array}$ & $\begin{array}{c}194 \\
(13.819)\end{array}$ & $\begin{array}{c}4 \\
(0.285)\end{array}$ & $\begin{array}{c}0 \\
(0.000)\end{array}$ & $\begin{array}{c}2 \\
(0.142)\end{array}$ \\
\hline 6 & 34 & 54 & 9736 & $\begin{array}{c}753 \\
(77.342)\end{array}$ & $\begin{array}{c}16 \\
(1.643)\end{array}$ & $\begin{array}{c}409 \\
(42.009)\end{array}$ & $\begin{array}{c}10 \\
(1.027)\end{array}$ & $\begin{array}{c}2 \\
(0.205)\end{array}$ & $\begin{array}{c}3 \\
(0.308)\end{array}$ \\
\hline 7 & 152 & 319 & $\begin{array}{c}6345 \\
8\end{array}$ & $\begin{array}{c}3923 \\
(61.820)\end{array}$ & $\begin{array}{c}130 \\
(2.049)\end{array}$ & $\begin{array}{c}1657 \\
(26.112)\end{array}$ & $\begin{array}{c}45 \\
(0.709)\end{array}$ & $\begin{array}{c}16 \\
(0.252)\end{array}$ & $\begin{array}{c}32 \\
(0.504)\end{array}$ \\
\hline All & 210 & 561 & $\begin{array}{c}1105 \\
37\end{array}$ & $\begin{array}{c}5594 \\
(50.607)\end{array}$ & 196 (1.773) & $\begin{array}{c}2484 \\
(22.472)\end{array}$ & $69(0.624)$ & $\begin{array}{c}22 \\
(0.199)\end{array}$ & $\begin{array}{c}44 \\
(0.398)\end{array}$ \\
\hline
\end{tabular}

343 CRBSI- catheter-related blood stream infection, HPN- home parenteral nutrition

344 All data expressed per 1000 catheter days 


\begin{tabular}{|c|c|c|c|c|}
\hline Cause of death & $\begin{array}{c}\text { HPN } \\
\text { Related }\end{array}$ & $\begin{array}{c}\text { Underlying IF } \\
\text { disease }\end{array}$ & Non-IF-related & Frequency \\
\hline Malignancy & 0 & 16 & 4 & $23(52.3 \%)$ \\
\hline Pneumonia & 0 & 0 & 11 & $11(25.0 \%)$ \\
\hline Cardiac & 0 & 0 & 2 & $2(4.5 \%)$ \\
\hline Post-transplant & 0 & 2 & 0 & $2(4.5 \%)$ \\
\hline Vasculitis & 0 & 2 & 0 & $2(4.5 \%)$ \\
\hline Gl Bleed & 0 & 1 & 0 & $1(2.3 \%)$ \\
\hline Intracerebral haemorrhage & 0 & 0 & 1 & $1(2.3 \%)$ \\
\hline Retroperitoneal haemorrhage & 0 & 1 & 0 & $1(2.3 \%)$ \\
\hline Urinary sepsis & 0 & 0 & 1 & $1(2.3 \%)$ \\
\hline Unknown & & 3 & & $3(6.8 \%)$ \\
\hline Total deaths & $0(0.0 \%)$ & $25(56.8 \%)$ & $19(43.2 \%)$ & $44(100.0 \%)$ \\
\hline
\end{tabular}

348 Gl-gastrointestinal, HPN- home parenteral nutrition, IF- intestinal failure 
Table 5: Classification of unplanned hospital admissions

352

\begin{tabular}{|c|c|c|c|c|}
\hline Unplanned admissions & $\begin{array}{c}\text { HPN } \\
\text { Related }\end{array}$ & $\begin{array}{c}\text { Underlying IF } \\
\text { disease }\end{array}$ & Non-IF-related & Frequency \\
\hline CVC related issues & 31 & 0 & 0 & $31(44.9 \%)$ \\
\hline Infection & 19 & 0 & 0 & $19(27.5 \%)$ \\
\hline Malpositioning & 4 & 0 & 0 & $4(5.8 \%)$ \\
\hline Exit site infection & 3 & 0 & 0 & $3(4.3 \%)$ \\
\hline Fracture & 3 & 0 & 0 & $3(4.3 \%)$ \\
\hline Occlusion & 1 & 0 & 0 & $1(1.4 \%)$ \\
\hline Placement & 1 & 0 & 0 & $1(1.4 \%)$ \\
\hline Venous thrombosis & 3 & 0 & 0 & $3(4.3 \%)$ \\
\hline $\begin{array}{l}\text { Abdominal pain } \\
\text { (Obstruction/distension, weight } \\
\text { loss, High stoma output) }\end{array}$ & 0 & 9 & 0 & $9(13.0 \%)$ \\
\hline $\mathrm{AKI}$ & 0 & 3 & 1 & $4(5.8 \%)$ \\
\hline Sepsis & 0 & 5 & 5 & $10(14.5 \%)$ \\
\hline Abdominal sepsis & 0 & 5 & 0 & $5(7.2 \%)$ \\
\hline Abdominal wall sepsis & 0 & 0 & 1 & $1(1.4 \%)$ \\
\hline Cellulitis & 0 & 0 & 1 & $1(1.4 \%)$ \\
\hline Perianal sepsis & 0 & 1 & 0 & $1(1.4 \%)$ \\
\hline Pneumonia & 0 & 0 & 2 & $2(2.9 \%)$ \\
\hline
\end{tabular}




\begin{tabular}{|c|c|c|c|c|}
\hline $\begin{array}{l}\text { Enteral feeding issues (change of } \\
\text { feed, failed DETF, feeding tube } \\
\text { issues) }\end{array}$ & 0 & 1 & 0 & 1 (1.4\%) \\
\hline Electrolyte imbalance & 0 & 3 & 0 & $3(4.3 \%)$ \\
\hline Re-feeding & 0 & 3 & 0 & $3(4.3 \%)$ \\
\hline HPN (start/alteration) & 0 & 1 & 0 & $1(1.4 \%)$ \\
\hline Deranged LFTs & 0 & 1 & 0 & $1(1.4 \%)$ \\
\hline Social & 0 & & 1 & $2(2.9 \%)$ \\
\hline Home Care (HPN) issue & 0 & 1 & 0 & \\
\hline Vasculitis flare up & 0 & 1 & 0 & $1(1.4 \%)$ \\
\hline Total unplanned admissions & $34(49.3 \%)$ & $28(40.6 \%)$ & $7(10.1 \%)$ & $69(100.0 \%)$ \\
\hline
\end{tabular}

353 AKI- acute kidney injury, CVC- central venous catheter, DETF- distal end tube feeding, HPN- home 354 parenteral nutrition; IF- intestinal failure, LFT- liver function tests, 
Table 6. Summary of regression analyses

\begin{tabular}{|c|c|c|c|c|c|c|}
\hline Covariate & $\begin{array}{c}\text { All-cause } \\
\text { admissions } \\
\mathrm{RR}^{\star} \\
(95 \% \mathrm{Cl}) \\
\text { [p-value] }\end{array}$ & $\begin{array}{c}\text { Unplanned } \\
\text { admissions } \\
\mathrm{RR}^{*} \\
(95 \% \mathrm{Cl}) \\
\text { [p-value] }\end{array}$ & $\begin{array}{c}\text { Days in } \\
\text { hospital (all- } \\
\text { cause) } \\
\mathrm{RR}^{\star} \\
(95 \% \mathrm{Cl}) \\
\text { [p-value] }\end{array}$ & $\begin{array}{c}\text { Days in } \\
\text { hospital } \\
\text { (unplanned) } \\
\mathrm{RR}^{*} \\
(95 \% \mathrm{Cl}) \\
\text { [p-value] }\end{array}$ & $\begin{array}{c}\text { CRBSI } \\
\mathrm{RR}^{\star} \\
(95 \% \mathrm{Cl}) \\
\text { [p-value] }\end{array}$ & $\begin{array}{c}\text { Death } \\
\mathrm{OR}^{\star} \\
(95 \% \mathrm{Cl}) \\
\text { [p-value] }\end{array}$ \\
\hline $\begin{array}{l}\text { Total HPN } \\
\text { days per week }\end{array}$ & $\begin{array}{c}1.12 \\
(0.99,1.26) \\
{[0.0688]}\end{array}$ & $\begin{array}{c}1.19 \\
(0.97,1.46) \\
{[0.0900]}\end{array}$ & $\begin{array}{c}1.50 \\
(1.26,1.78) \\
{[<0.0001]}\end{array}$ & $\begin{array}{c}1.39 \\
(1.10,1.75) \\
{[0.0060]}\end{array}$ & $\begin{array}{c}1.26 \\
(0.88,1.79) \\
{[0.2046]}\end{array}$ & $\begin{array}{c}1.10 \\
(0.82,1.47) \\
{[0.5150]}\end{array}$ \\
\hline $\begin{array}{l}\text { CVC care } \\
\text { (nurse care } \\
\text { vs self/family } \\
\text { care) }\end{array}$ & Not included & Not included & Not included & Not included & $\begin{array}{c}1.32 \\
(0.50,3.51) \\
{[0.5751]}\end{array}$ & Not included \\
\hline $\begin{array}{l}\text { Gender (male } \\
\text { vs female) }\end{array}$ & $\begin{array}{c}1.18 \\
(0.84,1.65) \\
{[0.3417]}\end{array}$ & $\begin{array}{c}1.17 \\
(0.70,1.95) \\
{[0.5545]}\end{array}$ & $\begin{array}{c}1.40 \\
(0.87,2.28) \\
{[0.1697]}\end{array}$ & $\begin{array}{c}1.84 \\
(0.96,3.53) \\
{[0.0682]}\end{array}$ & $\begin{array}{c}1.62 \\
(0.66,3.95) \\
{[0.2918]}\end{array}$ & $\begin{array}{c}2.23 \\
(1.05,4.74) \\
{[0.0385]}\end{array}$ \\
\hline $\begin{array}{l}\text { Diagnosis } \\
\text { (ref=other } \\
\text { diagnosis) }\end{array}$ & & & & & & \\
\hline $\begin{array}{l}\text { Crohn's } \\
\text { disease }\end{array}$ & $\begin{array}{c}1.01 \\
(0.64,1.57) \\
{[0.9792]}\end{array}$ & $\begin{array}{c}0.98 \\
(0.50,1.90) \\
{[0.9481]}\end{array}$ & $\begin{array}{c}1.04 \\
(0.55,1.96) \\
{[0.8986]}\end{array}$ & $\begin{array}{c}0.80 \\
(0.34,1.88) \\
{[0.6128]}\end{array}$ & $\begin{array}{c}1.02 \\
(0.33,3.21) \\
{[0.9664]}\end{array}$ & $\begin{array}{c}0.29 \\
(0.08,1.02) \\
{[0.0537]}\end{array}$ \\
\hline $\begin{array}{l}\text { Surgical } \\
\text { complicati } \\
\text { ons }\end{array}$ & $\begin{array}{c}1.03 \\
(0.70,1.52) \\
{[0.8844]}\end{array}$ & $\begin{array}{c}0.91 \\
(0.50,1.66) \\
{[0.7602]}\end{array}$ & $\begin{array}{c}1.05 \\
(0.60,1.83) \\
{[0.8620]}\end{array}$ & $\begin{array}{c}0.42 \\
(0.20,0.90) \\
{[0.0256]}\end{array}$ & $\begin{array}{c}1.05 \\
(0.36,3.06) \\
{[0.9355]}\end{array}$ & $\begin{array}{c}0.61 \\
(0.27,1.38) \\
{[0.2371]}\end{array}$ \\
\hline
\end{tabular}




\begin{tabular}{|c|c|c|c|c|c|c|}
\hline Covariate & $\begin{array}{c}\text { All-cause } \\
\text { admissions } \\
\mathrm{RR}^{\star} \\
(95 \% \mathrm{Cl}) \\
\text { [p-value] }\end{array}$ & $\begin{array}{c}\text { Unplanned } \\
\text { admissions } \\
\mathrm{RR}^{\star} \\
(95 \% \mathrm{Cl}) \\
\text { [p-value] }\end{array}$ & $\begin{array}{c}\text { Days in } \\
\text { hospital (all- } \\
\text { cause) } \\
\mathrm{RR}^{\star} \\
(95 \% \mathrm{Cl}) \\
{[p-\text { value] }}\end{array}$ & $\begin{array}{c}\text { Days in } \\
\text { hospital } \\
\text { (unplanned) } \\
\mathrm{RR}^{*} \\
(95 \% \mathrm{Cl}) \\
\text { [p-value] }\end{array}$ & $\begin{array}{c}\text { CRBSI } \\
\mathrm{RR}^{*} \\
(95 \% \mathrm{Cl}) \\
\text { [p-value] }\end{array}$ & $\begin{array}{c}\text { Death } \\
\text { OR }^{*} \\
(95 \% \mathrm{Cl}) \\
\text { [p-value] }\end{array}$ \\
\hline $\begin{array}{l}\text { Previous } \\
\text { CRBSI } \\
\text { (yes vs no) }\end{array}$ & Not included & Not included & Not included & Not included & Not included & $\begin{array}{c}2.34 \\
(0.65,8.47) \\
{[0.1951]}\end{array}$ \\
\hline $\begin{array}{l}\text { Time on HPN } \\
\text { (1000 days) }\end{array}$ & $\begin{array}{c}0.71 \\
(0.39,1.27) \\
{[0.2465]}\end{array}$ & $\begin{array}{c}0.89 \\
(0.34,2.31) \\
{[0.8053]}\end{array}$ & $\begin{array}{c}0.38 \\
(0.16,0.89) \\
{[0.0271]}\end{array}$ & $\begin{array}{c}1.35 \\
(0.43,4.20) \\
{[0.6092]}\end{array}$ & $\begin{array}{c}2.59 \\
(0.62,10.89) \\
{[0.2033]}\end{array}$ & $\begin{array}{c}0.14 \\
(0.02,0.79) \\
{[0.0270]}\end{array}$ \\
\hline BMI & Not included & Not included & Not included & Not included & $\begin{array}{c}1.00(0.91 \\
, 1.10) \\
{[0.9983]}\end{array}$ & Not included \\
\hline $\begin{array}{l}\text { Age of HPN } \\
\text { onset (years) }\end{array}$ & $\begin{array}{c}0.98 \\
(0.97,0.99) \\
{[0.0002]}\end{array}$ & $\begin{array}{c}0.98 \\
(0.97,1.00) \\
{[0.0675]}\end{array}$ & $\begin{array}{c}0.98 \\
(0.96,0.99) \\
{[0.0092]}\end{array}$ & $\begin{array}{c}1.00 \\
(0.97,1.02) \\
{[0.6866]}\end{array}$ & $\begin{array}{c}0.98 \\
(0.94,1.01) \\
{[0.1570]}\end{array}$ & $\begin{array}{c}1.04 \\
(1.01,1.07) \\
{[0.0087]}\end{array}$ \\
\hline
\end{tabular}

359

$360 \mathrm{Cl}$ - confidence interval, CRBSI- catheter related blood stream infection, CVC- central venous

361 catheter, HPN- home parenteral nutrition, OR- odds ratio, RR- relative rate.

362 * relative to reference category (categorical variable) or one unit increase (continuous variable);

363 yellow highlighting indicates variable of interest. 